\title{
Removal of Arsenic (III) Present in Ground Water of Bangladesh with Polymer Supported Hydrated Fe(III) Oxides
}

\author{
Mohammad Arifur Rahman*, Evanta Kabir and A. M. Shafiqul Alam \\ Department of Chemistry, Dhaka University, Dhaka-1000, Bangladesh
}

(Received: 14 October 2014; Accepted: 2 February 2015)

\begin{abstract}
In the present study, a technique to remove arsenic has been developed with a polymer-supported hydrated Fe(III) oxide (HFO) by using a strongly basic anionic exchanger IRA-420 as the host material and $\mathrm{FeCl}_{3}-\mathrm{HCl}-\mathrm{NaCl}$ solution as the reaction environment. The optimized conditions were applied to a sample collected from Sonargaon, Dhaka. The removal efficiency of this method was more than 80\%, which indicates that this method can be used as an efficient method for arsenic removal in Bangladesh. IRA-420-HFO exhibits more preferential adsorption of arsenic ions which is attributed to the Donnan membrane effect exerted by the host resin (IRA-420) as well as to the loaded HFO particles for specific interaction toward arsenic (III) ions. All the results indicated that HFO polymer derivative is an attractive adsorbent for efficient arsenic (III) removal from contaminated groundwater of Bangladesh.
\end{abstract}

Key words: Arsenic, adsorption, removal, anion exchanger, hydrated Fe(III) oxide.

\section{Introduction}

Arsenic in drinking water causes many health problems, such as lung and urinary bladder cancer, muscular weakness, nerve tissue injuries, Blackfoot disease, etc ${ }^{1,2}$. Therefore, the World Health Organization (WHO) has recommended a maximum contaminant level (MCL) for arsenic in drinking water of $50 \mu \mathrm{g} / \mathrm{L}$ for Bangladesh.

Arsenic present in natural waters is mainly in its inorganic forms, including arsenate and arsenite. Various treatment technologies have been developed to remove arsenic from water, including flocculation-precipitation, membrane separation, and adsorption ${ }^{3,4}$. In the past decades adsorption has attracted increasing interest, and adsorption on hydrated Fe(III) oxide (HFO) has been generally considered as a potential way for its high capacity for arsenic removal ${ }^{5-7}$. In addition, hydrated Fe(III) oxide or HFO is innocuous, inexpensive, readily available, and chemically stable over a wide $\mathrm{pH}$ range. Recent studies mentioned that Fe(III) oxides have high sorption affinity towards both As(V) or arsenates and As(III) or arsenites, which are Lewis bases (i.e., electron pair donors). The adsorption of As(III) onto HFO particles followed ligand exchange mechanism in the coordination spheres of Fe atoms ${ }^{5-7}$. Compared to crystalline forms of iron (III) oxides (namely, goethite, hematite, and magnetite), amorphous iron oxides have highest surface area per unit mass. Since sorption sites reside primarily on the surface, amorphous iron oxides (referred to as hydrated iron (III) oxides or HFO) offer the highest adsorption capacity on a mass basis ${ }^{6,7}$.

The particle sizes of the precipitated amorphous HFO particles were found in the range of $20-100 \mathrm{~nm}^{8}$. HFO showed high arsenic removal capacity, however their aggregates are unusable in fixed beds or any flow through systems when they were used as sorbents due to excessive pressure drops and weak mechanical strength ${ }^{8}$. To overcome the foregoing problems, HFO was always loaded on different porous materials, such as granular activated carbon 9 , cellulose ${ }^{10}$, alginate beads ${ }^{11}$ sand ${ }^{12}$, polymeric adsorbent 13,14 . However, little is known about the role of surface chemistry of host materials in arsenic removal. Sengupta and coworkers ${ }^{15}$ developed a novel hybrid sorbent based on Donnan membrane effect for arsenic removal. It was achieved by using strongly basic anion exchangers as supporting material, where the targeted anions would be pre-concentrated as a result of electrostatic interaction between the immobilized positively charged groups on the exchanger matrix and the targeted anions. However, $\mathrm{Fe}^{3+}$ as a traditional HFO precursor cannot directly enter into the pores of a strongly basic exchanger due to the charge expulsion. A proprietary technique was proposed by Sengupta $^{15}$ to successfully load HFO on a strongly basic exchanger and obtain a specific sorbent Arsen X for arsenic removal from contaminated water. However, all the removal methods were very complicated and expensive. Therefore, development of a simple arsenic removal method is required.

In the present study, we aimed at developing a hydrated Fe(III) hydroxide-loaded hybrid sorbent for efficient removal of arsenic from contaminated water. Arsenic removal by the new sorbent was evaluated by batch column experiments. Results indicated that the new sorbent exhibited an excellent sorption performance for arsenic removal.

\section{Experimental}

\section{Chemicals and Reagents}

All chemicals used in the study are of analytical grades. A basic porous anion exchange resin IR-420 (chloride form) cross-linked with divinylbezene was used in this experiment. De-ionized distilled water was used to prepare all solutions for this experiment. Standard $\mathrm{As}^{3+}$ ion solutions were prepared from $\mathrm{As}_{2} \mathrm{O}_{3}$ (Sigma Aldrich). All other chemicals were obtained from Sigma.

\section{Preparation of hydrated Fe(III) oxide sorbent}

The anion exchanger dispersed with HFO particles, referred to as HFO derivative, was fabricated according to the method reported elsewhere ${ }^{14}$. The procedure for the preparation of HFO consisted of the following four steps.

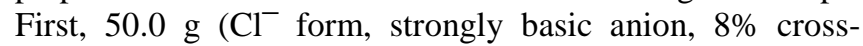
linking, 0.30-1.20 mm particle size, 14-52 dry mesh, BDH, England) IRA-420 beads were soaked into $500 \mathrm{~mL}$ aqueous solution containing $40 \mathrm{~g} \mathrm{FeCl}_{3}$. Tetrachloroferrate anion $\left(\mathrm{FeCl}_{4}{ }^{-}\right)$is readily formed in a ferric chloride solution in presence of an excess amount of hydrochloric acid or chloride. Tetrachloroferrate anion is relatively large in size 
and relatively weak hydrated anion ${ }^{15}$. $\mathrm{FeCl}_{4}{ }^{-}$is preferably loaded onto IRA-420 resin beads in aqueous solution in the presence of chloride ion ${ }^{16}$. Moreover, as the precursor of $\mathrm{HFO}, \mathrm{FeCl}_{4}^{-}$is decomposed in dilute $\mathrm{NaOH}$ solution or neutral solution. Then, Fe(III)-IRA-420 beads were filtered, vacuum desiccated, transferred to a $\mathrm{NaOH}-\mathrm{NaCl}$ solution (each at $7 \% \mathrm{w} / \mathrm{v}$ concentration), and then stirred for 24 hours. Fe(III) pre-loaded on IRA-420 was then precipitated as Fe(III) hydroxides in the inner surface of IRA-420. The resulting particles were rinsed with deionized water until the conductivity of the filtrate was close to that of the deionized water, followed by rinsing with 80:20 (v/v) ethanol-water solutions. Finally, the solid particles were thermally treated at $55{ }^{\circ} \mathrm{C}$ for $6 \mathrm{~h}$ and then vacuum desiccated to yield HFO spheres (Fig.1). HFO is formed in the inner surface of IRA420 beads according to the following reactions ${ }^{16}$ :

$$
\begin{aligned}
& \mathrm{FeCl}_{3(\mathrm{~s})}+\mathrm{Cl}^{-} \longrightarrow \mathrm{FeCl}_{4}^{-}{ }_{(\mathrm{aq})} \\
& \mathrm{R}^{+} \mathrm{Cl}_{(\mathrm{S})}^{-}+\mathrm{FeCl}_{4}^{-}{ }_{(\mathrm{aq})} \rightarrow \mathrm{R}^{+} \mathrm{FeCl}_{4}^{-}{ }_{(\mathrm{S})}+\mathrm{Cl}_{(\mathrm{aq})}^{-} \\
& \mathrm{R}^{+} \mathrm{FeCl}_{4}^{-}{ }_{(\mathrm{S})}+\mathrm{OH}_{(\mathrm{aq})}^{-} \rightarrow \mathrm{R}^{+} \mathrm{OH}_{(\mathrm{s})}^{-}+\mathrm{Fe}(\mathrm{OH})_{3(\mathrm{~s})}+\mathrm{Cl}_{(\mathrm{aq})}^{-}(3) \\
& \mathrm{Fe}(\mathrm{OH})_{3(\mathrm{~s})}+55^{\circ} \mathrm{C}(6 \mathrm{~h}) \rightarrow \mathrm{FeOOH}_{(\mathrm{s})}+\text { amorphous HFO } \\
& \text { particles }
\end{aligned}
$$

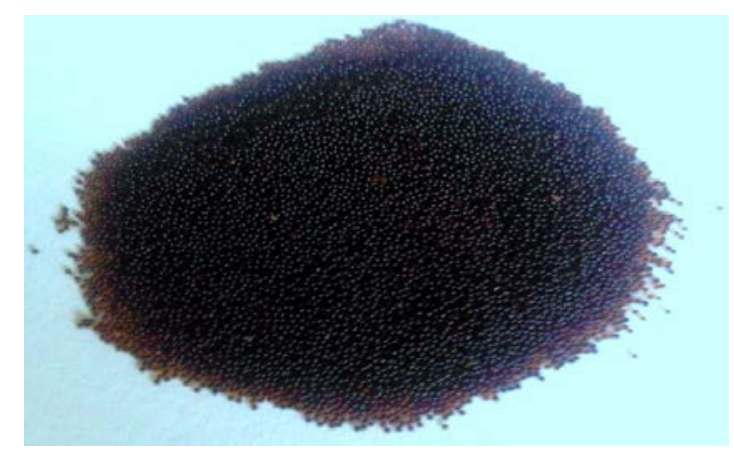

Fig. 1. IRA-420-HFO hybrid sorbent.

Sorption and analytical procedure

Hydrated iron(III) oxide loaded hybrid sorbent (HFO) (3 5 g) was added in a definite amount into the glass column of dimension (diameter $1.2 \mathrm{~cm} \times$ length $64.0 \mathrm{~cm}$ ). The sorption experiments were carried out in columns that were equipped with a stopper for controlling the flow rate (treatment rate). After the adjustment of $\mathrm{pH}$ to the desired value with $0.01 \mathrm{M}$ $\mathrm{HCl}$ and $0.01 \mathrm{M} \mathrm{NaOH}$ solutions, the sample solution (40 $\mathrm{mL}$ ) was passed through the adsorption column at a given flow rate. After the desired incubation period for each column experiment, the aqueous phases were separated from the materials, and the concentration of arsenic ions was measured using UV-Visible Spectrophotometer (UV-1800, Shimadzu, Japan) ${ }^{17}$. The removal of arsenic was calculated by using the following equation:

Removal efficiency $=\left[\left(\mathrm{C}_{0}-\mathrm{Ce}\right) / \mathrm{C}_{0}\right] \times 100(4)$

Where, $\mathrm{C}_{0}=$ concentration of the sample solution before treatment; $\mathrm{Ce}=$ concentration of the sample solution after treatment.

\section{Results and Discussion}

Characterization of hydrated Fe(III) oxide polymer adsorbent

The hybrid sorbent hydrated Fe(III) oxide (HFO) retained in the spherical resin and developed a deep blue colour, and the content of HFO loaded within IR-420 was about $14.92 \%$ in Fe mass.

Table 1. Salient properties of IR-420 and its derivative IR-420-HFO.

\begin{tabular}{ccc}
\hline Sorbent & IR-420 & IRA-420-HFO \\
\hline $\begin{array}{c}\text { BET surface area } \\
\left(\mathrm{m}^{2} \cdot \mathrm{g}^{-1}\right)\end{array}$ & 25.1 & 27.2 \\
Fe (III) content\% & 0 & 14.92 \\
Carbon (C)\% & 30.50 & 30.0 \\
Colour & White & Deep blue \\
\hline
\end{tabular}

The carbon content of HFO was determined by the EDX (Energy Dispersive X-ray Spectroscopy) (JEOL, Japan). Total iron content of the hybrid exchangers was determined with AAS (Atomic absorption spectroscopy, AAnalyst-800, Perkin Elmer, USA) after $\mathrm{H}_{2} \mathrm{SO}_{4}$ digestion. The BET surface area was measured by Surface area analyzer (Quanthachrome Nova 2200 e, USA). IRA-420- HFO particles possess possible active sites for the retention of heavy metal ions. Some other important properties of IR420 and IRA-420-HFO particles are given in Table 1.

\section{Effect of solution $\mathrm{pH}$}

$\mathrm{pH}$ is an important factor affecting heavy metals adsorption. $\mathrm{pH}$ affects the protonation of the functional groups of the adsorbent surface as well as the metal chemistry. The effect of $\mathrm{pH}$ on the $\mathrm{As}$ (III) ions adsorption was studied in the $\mathrm{pH}$ range of 2-7 as shown in Fig. 2.

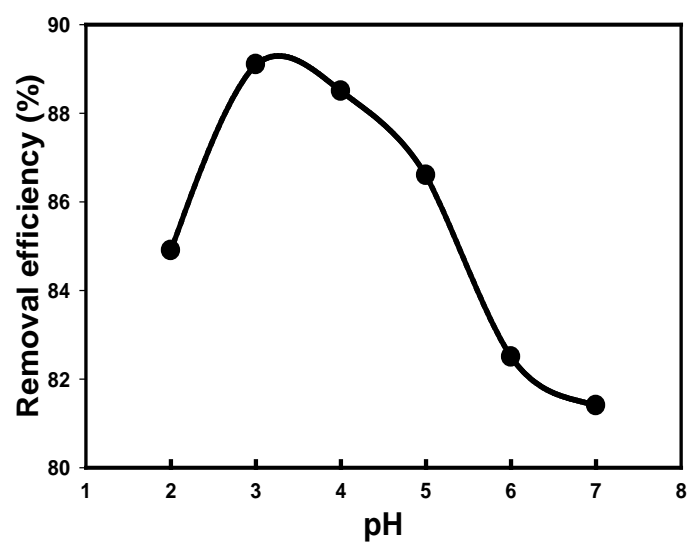

Fig. 2. Effect of pH on HFO adsorption toward As(III) at $301 \mathrm{~K}$. Initial concentration of each As solution was $100 \mu \mathrm{g} / \mathrm{L}$; Adsorbent dose was $4 \mathrm{~g} / 40 \mathrm{~mL}$

It can be seen that the adsorption of As(III) is most favoured in the $\mathrm{pH}$ range of $3.0-3.5$. About $\sim 88 \%$ of $\mathrm{As}(\mathrm{III})$ is removed under these conditions. It is thus clear that HFO 
polymer derivative can be effectively functioning under strong acidic condition ${ }^{18}$. IRA-420-HFO is composed of the host resin IR-420 and the impregnated HFO particles. Both can effectively adsorb $\mathrm{As}(\mathrm{III})\left[\mathrm{AsO}_{2}^{-}\right]$and $\mathrm{As}(\mathrm{V})\left[\mathrm{H}_{2} \mathrm{AsO}_{4}^{-}\right]$.

Generally, polymeric anion exchanger $\left[\left(\mathrm{R}_{4} \mathrm{~N}\right)^{+}\right.$: quaternary ammonium functional group] is an excellent substrate because it allows enhanced permeation of anions $\left(\mathrm{AsO}_{2}{ }^{-}\right)$ within the polymer phase due to high concentrations of fixed positive charges. The presence of high concentration of non-diffusing fixed charges $\left(\mathrm{R}^{+}\right)$in the polymer phase acts as a highly permeable interface for $\mathrm{AsO}_{2}{ }^{-}$and $\mathrm{H}_{2} \mathrm{AsO}_{4}{ }^{-}$ in the polymer phase ${ }^{14}$.

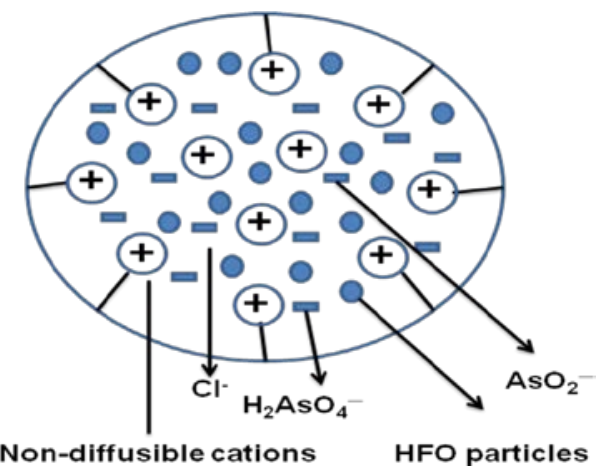

Fig. 3. Schematic of Permeation of anions into hybrid sorbent in the presence of non-diffusible cations (anion exchanger).

Fig. 3, provides a schematic illustration the permeation of As(III) and As(V) into anion exchanger. IRA-420-HFO has two distinctly different binding sites within polymer phase: first, covalently attached quaternary ammonium functional groups with high affinity toward hydrophobic anions such as perchlorate and second, surface hydroxyl groups of HFO with high affinity towards ligands such as arsenites and arsenates $^{15}$. HFO particles are considered to be a weak diprotic acid. According to Sengupta and coworkers ${ }^{14},{ }^{15}$ three surface functional groups of $\mathrm{HFO}$ (e.g., $\mathrm{FeOH}_{2}{ }^{+}$at $\mathrm{pH}$ $(<0.0-6.5)$; $\mathrm{FeOH}$ at $\mathrm{pH}(4.0-9.0)$; $\mathrm{FeO}$ at $\mathrm{pH}(<9.0-14.0))$ are produced at different $\mathrm{pH}$. It may be noted that in the $\mathrm{pH}$ range of 4.0-9.0, ligands (i.e., Lewis bases such as arsenates and arsenates) are selectively sorbed through the formation of inner-sphere complexes ${ }^{21}$. Above $\mathrm{pH}$ 9.0, negatively charged $\mathrm{FeO}^{-}$is the predominant surface functional group, thus rejecting all anions including arsenates and arsenates. In contrast, HFO is decomposed into ferrous ion under acidic solution $(>2.0)$ and therefore loses its sorption capacity gradually ${ }^{21}$.

From Fig. 2, we see that high acidity is unfavorable for As(III) adsorption onto the loaded HFOs. But the uptakes of arsenic $\left(\mathrm{As}^{3+}\right)$ ions on HFOs derivative are significant in the range of $\mathrm{pH}$ 3-5. It may be associated with the different $\mathrm{H}^{+}$ activities inside and outside the polymeric phase of nanopores ${ }^{22}$, and enables HFO derivative more active than the bulky HFO particles for the removal of As (III) from acidic solution. The above discussion implies that HFO derivative can work effectively under acidic condition in the range of $\mathrm{pH}$ 3-5.

\section{Donnan membrane principle and HFO}

The principle of Donnan membrane process is an extension of the second law of thermodynamics. However, it deals with completely ionized electrolytes in a heterogeneous system $^{23}$. Sengupta et al., ${ }^{8}$ simplified the principle to make the explanation more relevant to arsenic removal. They mentioned that if HFO particles are dispersed within a solid phase containing a high concentration of fixed (nondiffusing) $\mathrm{R}^{+}$groups, HFO will offer high arsenic (III) and arsenic (V) removal capacity. On the contrary, arsenic removal capacity of HFO particles will be greatly suppressed when it is dispersed within a solid phase with fixed $\mathrm{R}^{-}$groups ${ }^{14}$. In the present study, a strong base polymeric anion exchanger IRA-420-HFO with solid phase containing positively charged fixed quaternary ammonium functional groups showed the removal efficiency of $84 \%$ arsenic (III) (Fig. 4) because of permeation of arsenite into the hybrid sorbent IRA-420-HFO (Fig. 3). The removal of arsenic(III) by the sorbent (IRA-420-DFO) was due to the Donnan membrane effect by the host (IRA-420 resin) material along with DFO for sorption enhancement.

\section{Effect of initial concentration on removal efficiency}

Removal efficiency is greatly dependent on the initial concentration of metal ions. The effects of the initial concentration on the removal of arsenic with HFO derivative were investigated. The dependence on concentration of arsenic adsorption was studied by using the contact time of 100 min while keeping the parameters such as volume of the metal solution, flow rate and amount of adsorbent constant. The initial concentration was evaluated in the range of 50$150 \mu \mathrm{g} / \mathrm{L}$ and results are presented in Fig. 4.

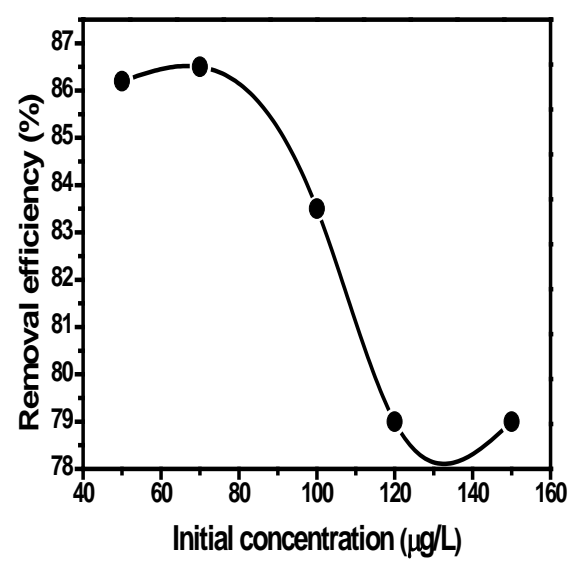

Fig. 4. Effect of initial concentration on HFO adsorption toward As(III) at $301 \mathrm{~K} . \mathrm{pH}=3.5$, contact time $=100 \mathrm{mins}$, the adsorbent dose $=4 \mathrm{~g} / 40 \mathrm{~mL}$.

The figure indicates that the percentage of arsenic removal decreases as the initial concentration of arsenic increases and higher removal efficiency was achieved with $70 \mu \mathrm{g} / \mathrm{L}$ of arsenic solution. Arsenic removal decreases as the initial concentration of arsenic increases; because the active sites are saturated at a certain concentration. As a result, at lower concentration most of the arsenic in the solution may contact with active sites of adsorbents. 


\section{Effect of contact time on removal efficiency}

The adsorption of arsenic (III) on HFO derivative as a function of their contact time was studied at 50, 70, 100, 150, 200 minute intervals, to determine the equilibrium time for the maximum uptake at $\mathrm{pH} 3.5$ and $\sim 28{ }^{\circ} \mathrm{C}$. It is clearly observed (Fig. 5) that removal efficiency varied significantly with different time when other parameters were constant. Contact time is an important parameter because as the As(III) solution comes into contact with the HFO derivative for a longer time the removal efficiency increases.

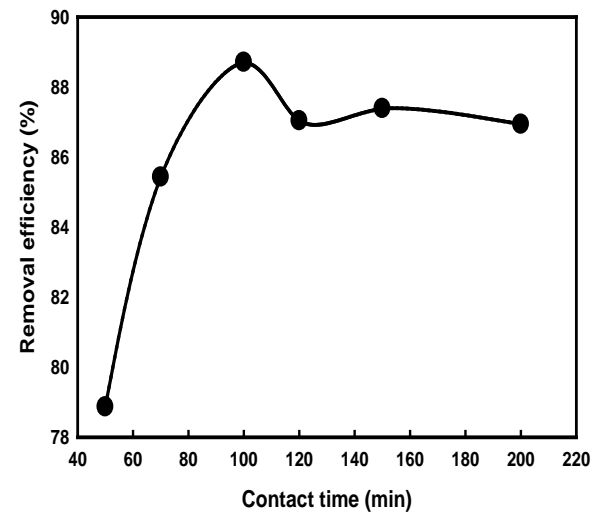

Fig. 5. Effect of contact time on HFO adsorption toward As (III) at $301 \mathrm{~K} \cdot \mathrm{pH}=3.5$, initial concentration $=100 \mu \mathrm{g} / \mathrm{L}$, adsorbent dose $=4 \mathrm{~g} / 40 \mathrm{~mL}$.

\section{Effect of adsorbent amount on removal efficiency}

The effects of the amount of adsorbent on the removal of arsenic (III) ion are shown in Fig. 6. As the adsorbent amount increased from 2.0 to $5.0 \mathrm{~g}$, the arsenic ions removal efficiency also increased from $75 \%$ to $86 \%$. Removal efficiency increases steeply with the increasing amount of adsorbent. This trend was expected because as the amount of adsorbent increased the HFO also increased and thereby enhanced the adsorption of arsenic. The removal efficiency increases in the range of 3-4.5 g. So, $4.0 \mathrm{~g}$ is considered as the optimized adsorbent amount for the present study.

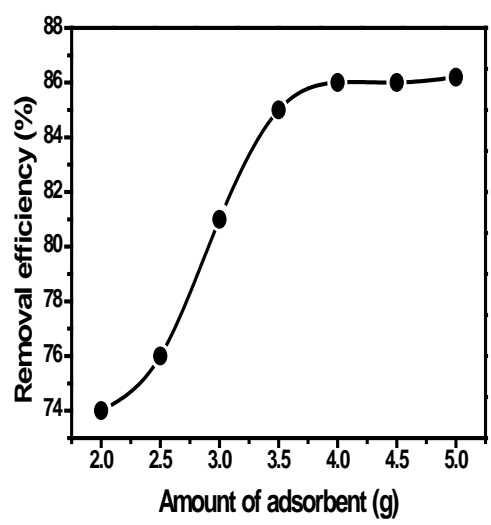

Fig. 6. Effect of adsorbent amount on HFO adsorption toward As(III) at $28{ }^{\circ} \mathrm{C} . \mathrm{pH}=3.5$, initial concentration $=100$ $\mu \mathrm{g} / \mathrm{L}$, contact time $=90 \mathrm{~min}$.

\section{Effect of flow rate on removal efficiency}

The effects of flow rate on the removal of arsenic (III) by adsorption onto polymer hybrid adsorbent HFO derivative are presented in Fig. 7. As the flow rate increased 0.5 to1.5 $\mathrm{mL} / \mathrm{min}$, the arsenic (III) removal efficiency decreased from $86 \%$ to $79 \%$. This is due to the fact as the flow rate increases the arsenic ions have little chance to come in contact with the HFO adsorption sites.

Application of the optimized condition for the removal of As from groundwater sample

The optimized conditions for the adsorption of As (III) ions on HFO derivative are summarized in the Table 2. The water sample was collected from Sonargaon, Dhaka. The water sample was passed through the HFO derivative polymer adsorbent containing in the adsorbent column respectively. To investigate the removal efficiency of arsenic by HFO derivative in environmental water samples (tube well water) was passed through the adsorbent. The results are given in the Table 3 . The result exhibits good removal efficiency from the ground water samples. Removal efficiency is more than $80 \%$, which proves the efficiency of the method for arsenic removal in Bangladesh.

Table 2. Optimized condition for the removal of As (III) ions onto HFO derivative.

\begin{tabular}{cc}
\hline Name of the parameter & Optimized value \\
\hline Initial volume & $40 \mathrm{~mL}$ \\
Flow rate & $0.5 \mathrm{~mL} / \mathrm{min}$ \\
Initial concentration & $100 \mu \mathrm{g} / \mathrm{L}$ \\
Contact time & $150 \mathrm{~min}$ \\
Adsorbent amount & $4.0 \mathrm{~g}$ \\
$\mathrm{pH}$ & 3.5 \\
\hline
\end{tabular}

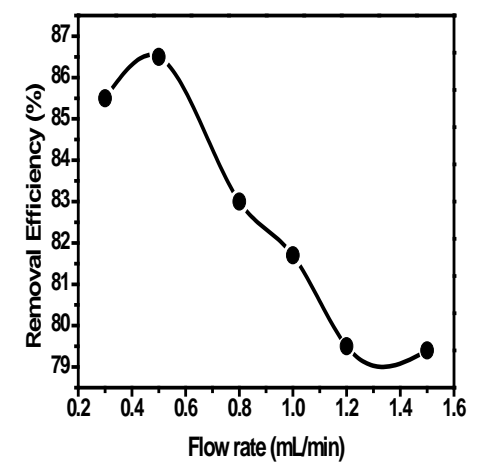

Fig. 7. Effect of flow rate on $\mathrm{HFO}$ adsorption toward $\mathrm{As}(\mathrm{III})$ at $28^{\circ} \mathrm{C}$. $\mathrm{pH}=3.5$, initial concentration $=100 \mu \mathrm{g} / \mathrm{L}$, contact time $=60$ min.

\section{Conclusion}

In the present study hydrous Fe (III) oxide (HFO) was successfully loaded on an anionic exchanger to obtained a hybrid adsorbent HFO for the removal of arsenic (III) from contaminated water. HFO showed effective adsorption 
capacity of arsenic(III) from contaminated groundwater. Column experiments showed that arsenic(III) adsorption on HFO could result in a concentration below $50 \mu \mathrm{g} / \mathrm{L}$, which was the maximum concentration limit set by WHO (World Health Organization) for Bangladesh. The removal efficiency is more than $80 \%$, therefore, HFO polymer derivative may be considered a suitable adsorbent for efficient arsenic(III) removal from contaminated groundwater.

Table 3. Removal of As(III) ions from tube well water (Sonargaon) by the developed Method*.

\begin{tabular}{cccccc}
\hline Sample & $\begin{array}{c}\text { Adso } \\
\text { rbent } \\
\text { (g) }\end{array}$ & $\begin{array}{c}\text { Sample } \\
\text { Volume } \\
\text { (mL) }\end{array}$ & $\begin{array}{c}\text { Conc. of } \\
\text { As (III) } \\
\text { before } \\
\text { passing } \\
\text { through } \\
\text { HFO, } \\
\boldsymbol{\mu g} / \mathbf{L}\end{array}$ & $\begin{array}{c}\text { Conc. of } \\
\text { As (III) } \\
\text { after } \\
\text { passing } \\
\text { through } \\
\text { HFO, } \mathbf{\mu g} / \mathbf{L}\end{array}$ & $\begin{array}{c}\text { Removal } \\
\text { efficiency } \\
\text { (\%) }\end{array}$ \\
\hline S1 & 4.0 & 40.0 & 130 & 17 & 86.51 \\
S2 & 4.0 & 40.0 & 150 & 22 & 84.73 \\
S3 & 4.0 & 40.0 & 160 & 22 & 86.42 \\
\hline
\end{tabular}

*S1, S2 and S3 were collected from samples sites.

\section{References}

1. Thomas, S. Y. C., T. G. Chuah, Y. Robiah, F. L. Gregory Koay, I. Azni, 2007. Arsenic toxicity, health hazards and removal techniques from water: An overview, Desalination, (1-3), 139-166.

2. Davis T. A., B. Volesky, A. Mucci, 2003. A review of the biochemistry of heavy metal biosorption by brown algae. Water Res., 37 (18), 4311-4330.

3. Liao, L. B., D. G. Fraser, 2005. Adsorption of arsenic on hydroxyl-Fe-montmori-llonite complexes. Sci. China Ser DEarth Sci, 35(8), 750-757.

4. Zhang, Y., M. Yang,, Y. X. Gao, 2003. Preparation and adsorption mechanism of rare earth-doped adsorbent for arsenic (V) removal from ground-water. Sci. China Ser BChem, 33(2), 127-133.

5. Dixit, S., J. G. Hering, 2003. Comparison of arsenic (V) and arsenic (III) sorption onto iron oxide minerals; implications for arsenic mobility. Environ. Sci. Technol., 37, 4182-4189.

6. Jain, A, K. P. Raven, R. H. Loeppert, 1999. Arsenita and arsenate adsorption on ferrihydrite: surface charge reduction and net $\mathrm{OH}^{-}$release stoichiometry, Environ. Sci. Technol., 33,1179-1184.

7. Goldberg, S, C. T. Johnston, 2001. Mechanism of arsenic adsorption on amorphous oxides evaluated using macroscopic measurements, virational spectroscopy, and surface complexation modeling, J. colloid. Interf. Sci., 234, 204-216.

8. Cumbal, L., A. K. SenGupta, 2005. Arsenic removal using polymer supported hydrated iron (III) oxide nanopartocles: Role of Donnan membrane effect. Environ. Sci. Technol., 39, 6508-6515.
9. Jia, Y., L. Xu, Z. Fang, 2006. Observation of surface precipitation of arsenate on ferrihydrite, Environ. Sci. Technol., 40, 3248-3253.

10. Gu, Z., J. Fang, B. Deng, 2005. Preparation and evaluation of GAC-based iron-containing adsorbents for arsenic removal. Environ. Sci. Technol., 39, 3833-3843.

11. Guo, X., F. Chen, 2005. Removal of arsenic by bead cellulose loaded with iron oxyhydroxide from groundwater. Environ. Sci. Technol., 39, 6808-6818.

12. Min, J, J. G. Hering, 1998. Arsenic sorption by Fe(III)-doped alginate gels. Water Res., 32, 1544-1552.

13. Lo, S, T. Jeng, L. Chin, 1997. Characteristics and adsorption properties of an iron coated sand. Water Sci. Technol., 35, 63-70.

14. DeMarco, M. J, A. K. Sengupta, J. E. Greenleaf, 2003. Arsenic removal using a polymeric/inorganic hybrid sorbent. Water Res., 37, 164-176.

15. Sengupta, A. K, L. Cumbal, Method of manufacture and use of hybrid anion exchanger for selective removal of contaminating ligands from fluids, US Patent Appl. 20050156136.

16. Zhang Q. J., B. C. Pan, X. Q. Chen, W. M. Zhang, B. J. Pan, 2008. Preparation of polymer-supported hydrated ferric oxide based on Donnan membrane effect and its application for arsenic removal, Sci. China Ser B-Chem, 51(4), 379-385.

17. Dhara, R. K. , Y. Zhenga, J. Rubenstonec, A. van Geenc, 2004. A rapid colorimetric method for measuring arsenic concentrations in groundwater, Analytica Chimica Acta, 526, 203-209.

18. Pan B., H. Qiu, 2010. Highly efficient removal of heavy metals by polymer supported HFO: behavior and XPS study, Water Res. , 44, 815-824.

19. Dabrowski,A., Z.Hubicki, P. Podkoscielny, and E. Robens, 2004. Selective removal of the heavy metal ions from water and industrial wastewater by ionexchangemethod.Chemosphere, 59, 91-106.

20. Trivedi, P., J. A. Dyer and D. L. Sparks. 2003. Lead adsorption onto ferrihydrite, 1 A macroscopic and spectroscopic assessment, Environ. Sci. Technol. 37, 908-914.

21. Dzombak, D. A., F. M. M Morel, Surface Complexation Modeling. Hydrous Ferric Oxide. Wiley, New York. 1990.

22. Molochnikov, L. S., E. G. Kovalyova, I. A. Grigorev, A. A. Zagorodni, 2004. Direct measurement of $\mathrm{H}^{+}$activity inside cross-linked functional polymers using nitoxide spin probes. J. Physical Chem. B, 108(4), 1302-1313.

23. Donnan, F. G., 1995. Theory of membrane equilibria and membrane potentials in the presence of non-dialysing electrolytes. A contribution to physical-chemical physiology, J. Membr. Sci. 100, 45-55. 